\title{
DENTAL FORUM
}

\section{Factors Associated with Dental Caries in Primary and Permanent Dentition in Patients Aged 2 to 12 Years who Attended a University Clinic \\ CT Hernández-Martínez ${ }^{1}$, NL Robles-Bermeo ${ }^{1}$, E Lara-Carrillo ${ }^{1}$, CE Medina-Solís, ${ }^{1,2}$ SJ Jiménez-Gayosso, ${ }^{1}$ AP Pontigo-Loyola, ${ }^{2}$ AA Vallejos-Sánchez. ${ }^{3}$}

\begin{abstract}
Objectives: To determine the factors associated with dental caries in the primary and permanent dentition of children attending a paediatric dentistry clinic at a public university in central Mexico.

Methods: A cross-sectional study was performed using the medical records from 309 patients aged 2 to 12 years who attended the Paediatric Dentistry Specialty Clinic at the Autonomous University of the State of Mexico between January 2014 and December 2015. The dependent variables were the experience of caries for each dentition (dmft index for primary dentition and DMFT index for permanent dentition), which were obtained from the clinical history in the diagnostic records. The independent variables were diverse sociodemographic, socioeconomic, and oral and general health indicators. Statistical analysis was performed using nonparametric tests in Stata.

Results: The mean age was $5.71 \pm 2.43$ years and $50.8 \%$ were men. The mean dmft index was $8.53 \pm 4.18$ (prevalence $=99 \%$ ), while the DMFT index was $1.91 \pm 2.02$ (prevalence=58.9\%). The variables age, number of siblings, presence of syndrome, dental pain experience, dental pain presence, as well as oral hygiene with help showed statistically significant differences with dmft. Similarly, age, number of siblings, and dental pain experience were statistically significant with DMFT.
\end{abstract}

Conclusions: The caries experience observed in this sample of self-selected patients was high. We identified several variables associated with dental caries in both dentitions.

Keywords: Dental caries, Mexico, oral health, paediatric dentistry

From: ${ }^{1}$ Advanced Studies and Research Centre in Dentistry, "Dr Keisaburo Miyata" of Faculty of Dentistry at Autonomous University State of Mexico, Toluca, Mexico. ${ }^{2}$ Academic Area of Dentistry of Health Sciences Institute at Autonomous University of Hidalgo State, Pachuca, Mexico. ${ }^{3}$ Faculty of Dentistry at Autonomous University of Campeche, Campeche, Mexico.

Correspondence: Mr C Medina-Solís, Academic Area of Dentistry of Health Sciences Institute, Autonomous University of Hidalgo State, Pachuca, Mexico. Email: cemedinas@yahoo.com 


\section{INTRODUCTION}

Dental caries is a dynamic process that involves cycles of demineralization and remineralization. These cycles are the product of a complex series of events on the surface of the tooth, originating in a continuous exposure to carbohydrate in the diet. This exposure produces an ecological change in the environment of the dental biofilm, turning a population of microorganisms balanced and with low cariogenicity into a highly cariogenic population. This leads to an increase in the production of organic acids from their metabolism, which are in contact with the hard tissues of the tooth, and produce loss of minerals; this finally leads to a carious lesion (1). In addition to biologic variables, other factors are related to the presence of dental caries, such as socioeconomic status, sex, age, oral hygiene, schooling, and age of the parents, health-disease knowledge, lack of regular visits to the dentist, and the presence of structural defects in the enamel $(2,3)$.

Dental caries is considered a public health problem around the world because of its high prevalence and incidence in all population groups (4). In Latin America, dental caries is the fourth most prevalent disease, and it shows the greatest burden of disease in the years of healthy life lost (5). However, information about the prevalence of dental caries is varied. In a recent meta-analysis that included 75 studies on caries prevalence in Latin American and Caribbean countries, it was observed that for primary dentition in children 5-6 years of age, the prevalence of caries was $70 \%$, and for permanent dentition in children aged 11-12 years, the prevalence was $63 \%(6)$.

Mexico is considered by the World Health Organization to be a country with a high prevalence of this disease (7). According to data from the Epidemiological Surveillance System of Oral Pathologies (SIVEPAB) of 2015 (8), in the age group from 1 to 10 years, the average dmft (decay, missing and filling teeth) index is 3.58 , of which 3.26 teeth were decayed, 0.06 were missing and 0.26 were filled. The largest component is caries, representing more than $90 \%$ of the total index for all age groups. The objective of the present study was to determine the factors 
associated with dental caries in the primary and permanent dentition of children attending at the Paediatric Dentistry Specialty Clinic of the Autonomous University of the State of Mexico.

\section{MATERIAL AND METHODS}

A cross-sectional study was performed in patients from 2 to 12 years of age. The sample was selected using non-probabilistic sampling. The sample size was calculated with a $95 \%$ confidence level, an accuracy of $4 \%$, a proportion (approximate value of the parameter) of $90 \%$, and an expected loss ratio of $10 \%$, which resulted in sample size of 314 subjects. The inclusion criteria for the clinical records were: a) individuals of either sex; b) all the elements of diagnosis were present; c) 2 to 12 years of age; and d) authorized by the clinic instructor for their treatment. The exclusion criteria were: a) clinical scores with confusing data or with information that had not been properly collected; and b) parents who did not authorize the taking of clinical photographs. The final sample was of 309 clinical records of patients who attended the Paediatric Dentistry Specialty Clinic at the Autonomous University of the State of Mexico between January 2014 and December 2015. This institution is in the City of Toluca de Lerdo, the capital of Mexico State, and it is the public university of the State. It provides specialized services for the general population at low cost, specifically for citizens of the region of all socioeconomic levels, although those of low and medium socioeconomic levels generally attend.

All data were obtained from the medical records that contained information provided by the parents/guardians. The dependent variables were dental caries experience for each dentition. The dmft index (decayed, missing, and filled teeth index in primary dentition), and DMFT index (decayed, missing, and filled teeth index in permanent dentition) were calculated, and both indices determine the present and past experience of caries through these components (9). The indices were 
obtained from diagnostic records in the clinical history that was compiled by the students in the specialty under the supervision of their teachers, and these were compared with clinical photographs. The independent variables included in the study were: age of the patient, family size (number of children), breastfeeding time (months reported by the parents/guardians), time of bottle feeding (months reported by the parents/guardians), number of brushing times (number reported by the parents/guardians), sex, previous visits to the dentist, unfavourable experiences in the dentist, reason for dental consultation, presence of syndromes, presence of dental pain at the time of going to the clinic, and oral hygiene with help.

The Stata 11.0 statistical package (StataCorp, Texas 77845 USA) was used to perform the data analysis. In the univariate analysis, frequencies and percentages were reported for the qualitative variables, as well as measures of central tendency and dispersion for quantitative variables. The non-parametric tests Mann-Whitney, Kruskal-Wallis, and Spearman correlation were used, according to the measurement scale of the variables that were tested.

The protocol was approved in the Autonomous University of the State of Mexico. This study complied with the scientific principles of the Declaration of Helsinki. Informed consent was not required because only clinical records were reviewed.

\section{RESULTS}

A total of 309 medical records were reviewed. Of these, $50.8 \%$ were men, and the mean age was $5.71 \pm 2.43$ years. Table I shows the results of the univariate analysis of the variables included in the study. The dmft index was $8.53 \pm 4.18$, and the DMFT index was $1.91 \pm 2.02$. The prevalence of caries in the primary dentition was $99 \%$, while that in the permanent dentition was $58.9 \%$. The 
largest component of the caries index in both dentitions was 'decayed teeth' (more than $85 \%$ ) (Table II).

Table III presents the results of the caries experience in the primary dentition ( $\mathrm{dmft}$ index). In the Spearman correlation test we observed that as age increases the $\mathrm{dmft}$ index decreases $(r=-0.2956 ; p<0.05)$, and when the family size increases the dmft decreases. Equally, significant differences $(p \leq 0.05)$ were observed when comparing the variable dmft index with the presence of any syndrome (with syndrome $=14.5 \pm 0.71$ vs. without syndrome $=8.49 \pm 4.16$ ). Children who had previous dental pain experience before the clinic visit showed a higher average dmft index $(9.38 \pm 3.99)$ than those who had no previous dental pain experience $(8.03 \pm 4.21 ; \mathrm{p}<0.05)$. Finally, when comparing the variable dmft and oral hygiene with help, a statistically significant difference was obtained $(p=0.002)$.

Table IV shows the results of experience of caries in the permanent dentition (DMFT index $)$. We found that the DMFT index was correlated with age $(r=0.521 ; p<0.05)$. It was observed that with a greater family size had a higher average of DMFT ( $\mathrm{r}=0.190 ; \mathrm{p}=0.050)$. Similarly, we observed that children with previous dental pain showed a higher amount of caries experience (2.53 \pm 2.05 vs. $1.53 \pm 1.92, \mathrm{p}<0.05)$.

\section{DISCUSSION}

This study was performed in a sample of subjects who require oral care services, and a high proportion of patients who had caries was observed. Additionally, several variables were identified as associated with dental caries in both dentitions. There are several factors associated with dental caries that have been previously reported $(3,4)$, and because of the complex interaction in its aetiology, eradication of caries is difficult. Having up-to-date information on oral diseases in 
children is a useful tool to help with establishing health promotion programs and preventive programs, as well as in the treatment of these diseases, and health workers should use all sources available to document them. Thus, epidemiological information exists in non-epidemiological sources, and this data could be useful to monitor the population oral health in cases where no other type of data can be accessed, as was the case in the present study. Similar to other reports (8), this study was performed on patients who required oral health services, and it was also observed that the major component of the dmft and DMFT indices was the 'decayed tooth' component, indicating a great need for dental care in this population.

The dmft index was $8.53 \pm 4.18$, which is high compared to another study carried out in Mexico, where the value obtained was 3.58 (7). Similarly, studies around the world, in population that did not require health services, showed lower values than in Brazil (10) where a dmft index of 1.23 was reported or in Paraguay (11), a dmft index of 2.54 was observed in schoolchildren. This may be because the sample was obtained from a population that required health services, and consequently the individuals have a higher incidence of caries (12). The DMFT reported in the present study was $1.91 \pm 2.02$, which was similar to observed in Canada (1.8), but relatively low compared to reported around the world, such as Panama (3.64), Colombia (2.30), Peru (3.09), Uruguay (4.2), and Paraguay (3.8) (13). This may be because the patients in our study underwent dental replacement, which decreases the number of permanent teeth, resulting in a decrease in the DMFT index.

The relationship between $\mathrm{dmft}$ and age shows a slight negative correlation; $\mathrm{dmft}$ decreased as age increased, which is like previous studies (14). This could be because as age increases, the number of temporary teeth decreases. To observe and verify the previously described information, an analysis was performed where the patients were divided into age groups: from 2 to 5 years and from 6 to 12 years. In this analysis, a correlation of $r=0.1686(p=0.0449)$ was obtained 
between the age and dmft for the first group and $\mathrm{r}=-0.3244(\mathrm{p}<0.0001)$ for the second group. In the present study, as age increased, DMFT also increased. Other authors also reported similar findings (15), which is reasonable because older age allows longer exposure to the oral acid environment, which was also reported by other authors.

In contrast, and surprisingly, to other studies (16), the dmft index increased in children who received help from their parents when performing oral hygiene. This observation may be because of temporal ambiguity that occurs in a cross-sectional study, which is caused by measuring both cause and effect at the same time. In those children whose parents detected the presence of cavities, they participated more in their children's oral hygiene to try to solve the problem, but the disease was already present.

Similar to other studies (17), there was a relationship between the presence of syndromes and an increase in the caries index. In patients with special needs, it has been consistently observed that they present oral health deficiencies and high treatment needs, coupled with a lack of adequate oral hygiene (18). Therefore, attention to oral health should have special emphasis in these patients to improve their condition.

As reported in other studies (19), dental pain experience was related to high caries rates, this can be explained because many individuals who come to the Paediatric Dentistry Specialty Clinic of the university seeking restorative dental care, which indicates that the population has little information about the health-disease process because the patients seek attention in the acute period. Thus, the pain experience is a good risk indicator of the existence of dental disease. In México, too is reported that preventive dental services utilisation is very low (20).

The present study has limitations that need to be considered to correctly interpret the results. The study design, which was cross-sectional, presents the problem of temporal ambiguity, which refers to simultaneously measuring cause and effect. Thus, it is not possible to establish 
causal relationships. On the other hand, the associated indicators were analysed using data collected in the clinical records. The medical records obtained directly from the parents or guardians of the patients who came for dental care. However, different people administered the questionnaires. This could be a limitation in the study because of the wide range of perspectives included and although they were dentists, the assessment criteria for caries rates were not standardised. Additionally, using clinical chart data limits the magnitude of the study and may lead to biases.

\section{CONCLUSION}

Considering the limitations and based on the results, it can be concluded that a high experience of dental caries was observed in this sample of children who required oral health services. The experience of dental pain is an indicator of the risk of dental caries.

\section{ACKNOWLEDGEMENTS}

The field work and analysis was supported in part by a Scholarship from the National Council of Science and Technology (CONACyT).

\section{AUTHORS' NOTE}

CT Hernández-Martínez and CE Medina-Solís were involved in the design and development of the study, analysis, and interpretation of the results, both wrote the first draft of the manuscript. NL Robles-Bermeo, E Lara-Carrillo, SJ Jiménez-Gayosso, AP Pontigo-Loyola, and AA VallejosSánchez were involved in the conceptualisation of the paper, analysis, and interpretation of the 
results. All the authors were involved in the critical review and made intellectual contributions, and they also accepted the final version. The authors declare that they have no conflicts of interest. 


\section{REFERENCES}

1. Innes NP, Frencken JE, Bjørndal L, Maltz M, Manton DJ, Ricketts D et al. Managing carious lesions: Consensus recommendations on terminology. Adv Dent Res 2016; 28: 4957.

2. Elidrissi SM, Naidoo S. Prevalence of dental caries and toothbrushing habits among preschool children in Khartoum State, Sudan. Int Dent J 2016; 66: 215-20.

3. Cogulu D, Ersin NK, Uzel A, Eronat N, Aksit S. A long-term effect of caries related factors in initially caries-free children. Int J Paediatr Dent 2008; 18: 361-7.

4. Herrera MS, Medina-Solís CE, Robles-Bermeo NL, Lara-Carrillo E, Guadarrama-Quiroz LJ, Navarrete-Hernandez JJ. Indicators of oral hygiene and preventive dental care as variables associated with the high severity of caries. West Indian Med J 2017; Epub ahead of print. DOI: $10.7727 /$ wimj.2017.072

5. Gómez-Dantés H, Castro MV, Franco-Marina F, Bedregal P, Rodríguez-García J, Espinoza A et al. La carga de la enfermedad en países de América Latina. Salud Publica Mex 2011; 53: $72-7$.

6. Gimenez T, Bispo BA, Souza DP, Viganó ME, Wanderley MT, Mendes FM et al. Does the decline in caries prevalence of Latin American and Caribbean children continue in the new century? Evidence from systematic review with meta-analysis. PLoS One 2016; 11: e0164903

7. Pérez-Dominguez J, González-García A, Niebla-Fuentes MR, Ascencio-Montiel IJ. Encuesta de prevalencia de caries dental en niños y adolescents. Rev Med Inst Mex Seguro Soc 2010; 48: 25-9. 
8. Secretaría de salud; Subsecretaría de prevención y promoción de la salud. Resultados del Sistema de vigilancia epidemiológica de patologías bucales SIVEPAB 2015. Ciudad de México (México); 2015.

9. WHO. Oral health survey-basics methods. 5th Ed. Geneva: World Health Organization; 2013.

10. Siqueira MFG, Jardim MCA, Sampaio FC, Vasconcelos LCS, Vasconcelos LC. Evaluation of an oral health program for children in early childhood. Rev Odonto Ciênc 2010; 25: 3504.

11. Ferreira-Gaona MI, Diaz-Reissner CV, Pérez-Bejarano NM, Sanabria-Vázquez DA, Alvarenga-Rodas MV, Bazán-Cohene DD et al. Salud bucal en preescolares y nivel de conocimiento sobre higiene bucal de sus madres, en escuelas públicas y privadas de San Lorenzo, Paraguay. Pediatr (Asunción) 2016; 43: 129-36.

12. Schroth RJ, Cheba V. Determining the prevalence and risk factors for early childhood caries in a community dental health clinic. Pediatr Dent 2007; 29: 387-96.

13. Estupiñan-Day S. Promoting oral health: The use of fluoridation to prevent dental caries. Pan American Health Organization, Scientific and technical publication no. 615. Washington, DC: PAHO; 2005.

14. Herrera MS, Medina-Solis CE, Minaya-Sánchez M, Pontigo-Loyola AP, Villalobos-Rodelo JJ, Islas-Granillo H, et al. Dental plaque, preventive care, and tooth brushing associated with dental caries in primary teeth in schoolchildren ages 6-9 years of Leon, Nicaragua. Med Sci Monit 2013; 19: 1019-26.

15. Eslamipour F, Borzabadi-Farahani A, Asgari I. The relationship between aging and oral health inequalities assessed by the DMFT index. Eur J Paediatr Dent 2010; 11: 193-9. 
16. Elidrissi SM, Naidoo S. Prevalence of dental caries and toothbrushing habits among preschool children in Khartoum State, Sudan. Int Dent J 2016; 66: 215-20.

17. Mathias MF, Simionato MF, Guaré RO. Some factors associated with dental caries in the primary dentition of children with Down syndrome. Eur J Paediatr Dent 2011; 12: 37-42.

18. da Silva SN, Gimenez T, Souza RC, Mello-Moura AC, Raggio DP, Morimoto S, et al. Oral health status of children and young adults with autism spectrum disorders: systematic review and meta-analysis. Int J Paediatr Dent 2016; in press. doi: 10.1111/ipd.12274

19. Ortiz FR, Tomazoni F, Oliveira MDM, Piovesan C, Mendes F, Ardenghi TM. Toothache, associated factors, and its impact on oral health-related quality of life (OHRQoL) in preschool children. Braz Dent J 2014; 25: 546-53.

20. Casanova-Rosado AJ, Medina-Solís CE, Casanova-Rosado JF, Ávila-Burgos L, VallejosSánchez AA, Márquez-Rodríguez S, et al. Socioeconomic inequality in professionally administered topical fluoride among Mexican schoolchildren. West Indian Medical Journal 2017; 66 (2): in press. DOI: 10.7727/wimj.2014.361 
Table 1: Descriptive analysis for the study variables

\begin{tabular}{|c|c|c|}
\hline Variable & Mean & SD \\
\hline Age & 5.71 & 2.43 \\
\hline Family size (number of children) & 1.37 & 1.03 \\
\hline Breastfeeding time (months) & 9.11 & 7.40 \\
\hline Time of bottle feeding (months) & 12.38 & 11.32 \\
\hline \multirow[t]{2}{*}{ Frequency of tooth brushing per day } & 2.71 & 0.71 \\
\hline & Frequency & Percent \\
\hline \multicolumn{3}{|l|}{ Sex } \\
\hline Male & 157 & 50.8 \\
\hline Female & 152 & 49.2 \\
\hline \multicolumn{3}{|l|}{ Previous visits to the dentist } \\
\hline No & 157 & 50.8 \\
\hline Yes & 152 & 49.2 \\
\hline \multicolumn{3}{|l|}{ Unfavourable experiences at the dentist } \\
\hline No & 99 & 65.1 \\
\hline Yes & 53 & 34.9 \\
\hline \multicolumn{3}{|l|}{ Reason for dental visit } \\
\hline Pain & 68 & 22.0 \\
\hline Check up & 62 & 20.1 \\
\hline Rehabilitation & 119 & 38.05 \\
\hline Other & 60 & 19.4 \\
\hline \multicolumn{3}{|l|}{ Presence of syndromes } \\
\hline No & 307 & 99.4 \\
\hline Yes & 2 & 0.60 \\
\hline \multicolumn{3}{|l|}{ Dental pain experience } \\
\hline No & 195 & 63.1 \\
\hline Yes & 114 & 36.9 \\
\hline \multicolumn{3}{|l|}{ Presence of dental pain (present) } \\
\hline No & 270 & 87.4 \\
\hline Yes & 39 & 12.6 \\
\hline \multicolumn{3}{|l|}{ Oral hygiene with help } \\
\hline No & 156 & 50.5 \\
\hline Yes & 153 & 49.5 \\
\hline
\end{tabular}

Table 2: Analysis of the dmft and DMFT index components

\begin{tabular}{lllll}
\hline DMFT & Decayed & Missing & Filled & DMFT $>$ 0 \\
\hline $8.53 \pm 4.18$ & $7.49 \pm 4.209$ & $0.16 \pm 0.609$ & $0.88 \pm 1.79$ & $99 \%(\mathrm{n}=303)$ \\
DMFT & Decayed & Missing & Filled & DMFT $>$ 0 \\
$1.91 \pm 2.02$ & $1.68 \pm 1.831$ & $0.00 \pm 0.000$ & $0.22 \pm 0.816$ & $58.9 \%(\mathrm{n}=63)$ \\
\hline
\end{tabular}


Table 3: Bivariate analysis of the DMFT index through the independent variables included in the study

\begin{tabular}{|c|c|c|}
\hline Variable & dmft & p-value \\
\hline Age & $\mathrm{r}=-0.2956$ & $0.001 *$ \\
\hline Family size (number of children) & $\mathrm{r}=-0.169$ & $0.003 *$ \\
\hline Breastfeeding time (months) & $\mathrm{r}=-0.014$ & $0.795^{*}$ \\
\hline Time of bottle feeding (months) & $\mathrm{r}=0.108$ & $0.057 *$ \\
\hline Frequency of tooth brushing per day & $\begin{array}{c}r=0.032 \\
\text { Mean } \pm \text { SD }\end{array}$ & $0.577 *$ \\
\hline \multicolumn{3}{|l|}{ Sex } \\
\hline Male & $8.75 \pm 4.28$ & \\
\hline Female & $8.29 \pm 4.07$ & $0.446 \dagger$ \\
\hline \multicolumn{3}{|l|}{ Previous visits to the dentist } \\
\hline No & $8.54 \pm 3.91$ & \\
\hline Yes & $8.50 \pm 4.45$ & $0.564 \dagger$ \\
\hline \multicolumn{3}{|l|}{ Unfavourable experiences at the dentist } \\
\hline No & $8.54 \pm 4.55$ & \\
\hline Yes & $8.45 \pm 4.31$ & $0.943 \dagger$ \\
\hline \multicolumn{3}{|l|}{ Reason for dental visit } \\
\hline Pain & $8.64 \pm 4.09$ & \\
\hline Check up & $9.02 \pm 4.09$ & \\
\hline Rehabilitation & $8.04 \pm 4.49$ & \\
\hline Other & $8.86 \pm 3.67$ & $0.307 \S$ \\
\hline \multicolumn{3}{|l|}{ Presence of syndromes } \\
\hline No & $8.49 \pm 4.16$ & \\
\hline Yes & $14.5 \pm 0.71$ & $\mathbf{0 . 0 3 8} \dagger$ \\
\hline \multicolumn{3}{|l|}{ Dental pain experience } \\
\hline No & $8.03 \pm 4.21$ & \\
\hline Yes & $9.38 \pm 3.99$ & $0.003 \dagger$ \\
\hline \multicolumn{3}{|l|}{ Presence of dental pain (present) } \\
\hline No & $8.48 \pm 4.22$ & \\
\hline Yes & $8.81 \pm 3.91$ & $0.652 \dagger$ \\
\hline \multicolumn{3}{|l|}{ Oral hygiene with help } \\
\hline No & $7.71 \pm 3.91$ & \\
\hline Yes & $9.35 \pm 4.29$ & $0.002 \dagger$ \\
\hline
\end{tabular}

* Spearman's rho

$\dagger$ Mann-Whitney

$\S$ Kruskal-Wallis 
Table 4: Bivariate analysis of the $\mathrm{dmft}$ index through the independent variables included in the study

\begin{tabular}{|c|c|c|}
\hline Variable & DMFT & p-value \\
\hline Age & $\mathrm{r}=0.521$ & $0.001 *$ \\
\hline Family size (number of children) & $\mathrm{r}=0.190$ & $0.050 *$ \\
\hline Breastfeeding time (months) & $\mathrm{r}=0.795$ & $0.221 *$ \\
\hline Time of bottle feeding (months) & $\mathrm{r}=0.008$ & $0.930 *$ \\
\hline Frequency of tooth brushing per day & $\begin{array}{l}\mathrm{r}=-0.058 \\
\text { Mean } \pm \text { SD }\end{array}$ & $0.549 *$ \\
\hline \multicolumn{3}{|l|}{ Sex } \\
\hline Male & $2.01 \pm 2.05$ & \\
\hline Female & $1.79 \pm 1.99$ & $0.665 \dagger$ \\
\hline \multicolumn{3}{|l|}{ Previous visits to the dentist } \\
\hline No & $1.54 \pm 2.09$ & \\
\hline Yes & $2.06 \pm 1.97$ & $0.129 \dagger$ \\
\hline \multicolumn{3}{|l|}{ Unfavourable experiences at the dentist } \\
\hline No & $2.07 \pm 2.01$ & \\
\hline Yes & $2.04 \pm 1.93$ & $0.917 \dagger$ \\
\hline \multicolumn{3}{|l|}{ Reason for dental visit } \\
\hline Pain & $1.86 \pm 2.01$ & \\
\hline Check up & $1.75 \pm 2.42$ & \\
\hline Rehabilitation & $2.22 \pm 2.00$ & \\
\hline Other & $1.63 \pm 1.92$ & $0.629 \S$ \\
\hline \multicolumn{3}{|l|}{ Presence of syndromes } \\
\hline No & $1.91 \pm 2.02$ & \\
\hline Yes & $1.00 \pm 0.00$ & $0.919 \dagger$ \\
\hline \multicolumn{3}{|l|}{ Dental pain experience } \\
\hline No & $1.53 \pm 1.92$ & \\
\hline Yes & $2.53 \pm 2.05$ & $0.023 \dagger$ \\
\hline \multicolumn{3}{|l|}{ Presence of dental pain (present) } \\
\hline No & $1.80 \pm 1.97$ & \\
\hline Yes & $2.53 \pm 2.23$ & $0.160 \dagger$ \\
\hline \multicolumn{3}{|l|}{ Oral hygiene with help } \\
\hline No & $2.00 \pm 2.02$ & \\
\hline Yes & $1.52 \pm 2.02$ & $0.340 \dagger$ \\
\hline
\end{tabular}

* Spearman's rho

$\dagger$ Mann-Whitney

$\S$ Kruskal-Wallis 